\title{
Induction of early Purkinje cell dendritic differentiation by thyroid hormone requires ROR $\alpha$
}

\author{
Fatiha Boukhtouche ${ }^{1,2,3^{*}}$, Bernard Brugg ${ }^{1,2}$, Rosine Wehrlé ${ }^{1,2}$, Brigitte Bois-Joyeux ${ }^{4}$, Jean-Louis Danan ${ }^{4}$, \\ Isabelle Dusart ${ }^{1,2}$, Jean Mariani ${ }^{1,2,5}$
}

\begin{abstract}
Background: The active form $\left(T_{3}\right)$ of thyroid hormone $(T H)$ controls critical aspects of cerebellar development, such as migration of postmitotic neurons and terminal dendritic differentiation of Purkinje cells. The effects of $T_{3}$ on early dendritic differentiation are poorly understood.

Results: In this study, we have analyzed the influence of $T_{3}$ on the progression of the early steps of Purkinje cell dendritic differentiation in postnatal day 0 organotypic cerebellar cultures. These steps include, successively, regression of immature neuritic processes, a stellate cell stage, and the extension of several long and mature perisomatic protrusions before the growth of the ultimate dendritic tree. We also studied the involvement of $R O R \alpha$, a nuclear receptor controlling early Purkinje cell dendritic differentiation. We show that $T_{3}$ treatment leads to an accelerated progression of the early steps of dendritic differentiation in culture, together with an increased expression of ROR $\alpha$ (mRNA and protein) in both Purkinje cells and interneurons. Finally, we show that $T_{3}$ failed to promote early dendritic differentiation in staggerer ROR $\alpha$-deficient Purkinje cells.
\end{abstract}

Conclusions: Our results demonstrate that $T_{3}$ action on the early Purkinje cell dendritic differentiation process is mediated by $R O R \alpha$.

\section{Background}

The thyroid hormone (TH) L-3,3',5-triiodothyronine $\left(\mathrm{T}_{3}\right)$ is essential for normal central nervous system development [1], regulating processes associated with brain differentiation, such as neuronal migration, axonal and dendritic growth, synaptogenesis, and myelination [2]. In particular, $\mathrm{TH}$ plays an important role in cerebellar neurogenesis [3-5], a mainly postnatal developmental process. As a consequence, perinatal hypothyroidism affects the morphogenesis of cerebellar neurons (in particular the dendritic arborization of the Purkinje cells (PCs), which display a striking reduction in the growth and branching of their dendritic arborization [6]) and delays synaptic formation between PCs and granule cells [3-5,7] (for review, see [8]). Recent studies have demonstrated that THs promote this growth of the PC mature dendritic tree through activation of the nuclear thyroid hormone receptor (TR) TR $\alpha 1[9,10]$.

\footnotetext{
* Correspondence: fatiha.boukhtouche@gmail.com

'UPMC Université Paris 6, UMR 7102 NPA, F-75005, Paris, France
}

Shortly after birth, cerebellar PCs display a bipolar shape reminiscent of their migratory morphology. These immature PCs then follow a process of dendritic regression, prior to extending dendrites from which the ultimate and characteristic mature dendritic tree will arise (for review, see [11]). We have recently demonstrated that the nuclear receptor Retinoic acid receptor-related orphan receptor alpha (ROR $\alpha, \mathrm{NR} 1 \mathrm{D} 1)$ controls the early dendritic differentiation steps, particularly the regressive phase of this process [12]. The loss-of-function staggerer (sg) mutation in the Rora gene leads to cerebellar developmental defects in the mouse, including dramatic PC and granule cell loss [13-16]. Interestingly, cross-talk between the TH pathway and ROR $\alpha$ has been shown. In hypothyroid rats, daily thyroxine $\left(\mathrm{T}_{4}\right)$ replacement accelerates the increase of ROR $\alpha$ mRNA within the developing cerebellum, most obviously at P15 [17]. In the homozygous staggerer mutant mouse ( Rora $^{\text {sg/sg }}$ ), despite both normal TR expression [14] and normal serum TH levels [18], staggerer neurons seem to be unresponsive to $\mathrm{TH}$ treatment [19]. 
Despite the detailed description of cerebellar abnormalities due to hypothyroidism, most studies investigate the role of $\mathrm{TH}$ in the growth of the mature PC dendritic tree, which involves cross-talk and synaptogenesis with granule cells; but little is known about the effect of $\mathrm{TH}$ on early dendritic differentiation. In this study, we aimed at determining the role of $\mathrm{TH}$ in early $\mathrm{PC}$ dendritic differentiation, that is, during the phase of regression of the primary dendrite, and we studied the involvement of ROR $\alpha$ in this process. Using organotypic cultures, we have thus studied the progression of PC dendritic differentiation in the presence or absence of $\mathrm{T}_{3}$, and we observed an acceleration of the process of dendritic differentiation when $\mathrm{T}_{3}$ was added onto postnatal day 0 (P0) cerebellar slices for both early events (regression of the primary dendrite observed after 3 days in vitro (DIV)) and later ones (growth of the mature dendritic tree). We further propose that the accelerated early dendritic differentiation is dependent on a $\mathrm{T}_{3}$-induced increase of ROR $\alpha$ expression.

\section{Results}

Determination of the optimal $\mathrm{T}_{3}$ concentration to promote PC dendritic growth in organotypic culture

At birth, in vivo, most murine PCs are fusiform (bipolar shape, stage I; data not shown), as described for rats [20]. When cultured at P0 and kept in organotypic cultures, PCs present first an immature morphology (bipolar fusiform, stage I), then retract their primitive dendrites to become stellate or atrophic (stage II), elongate numerous long and mature dendritic perisomatic protrusions (stage III), and finally develop their ultimate dendritic trees (stage IV) [12].

In organotypic cultures, after 7 days in a serum-containing medium, PCs were mostly in stage II (stellate or atrophic stage), whereas almost no stage III PCs were observed. In order to explore the involvement of $\mathrm{T}_{3}$ in dendritic differentiation (that is, before the extension of the ultimate dendritic tree in stage IV), cultures from P0 animals were prepared and kept 7 DIV under serumfree conditions, with or without addition of $\mathrm{T}_{3}$ at different concentrations. Cultures were then fixed and immunolabeled with an anti-calbindin (anti-CaBP) antibody to visualize PCs.

In P0 slices cultivated without $\mathrm{T}_{3}$, most PCs (76\%) displayed 'stellate or atrophic' dendrites after 7 DIV (stage II; Figure $1 \mathrm{~A}, \mathrm{~B})$. Adding $\mathrm{T}_{3}$ at a concentration of $3 \mathrm{nM}$ did not dramatically modify the repartition of $\mathrm{PC}$ classes (Figure 1C,D). In contrast, supply of $30 \mathrm{nM}$ of $\mathrm{T}_{3}$ led to a significant acceleration of the dendritic differentiation since we observed that only $27 \%$ of PCs were in stage II, whereas $39 \%$ displayed long dendritic perisomatic protrusions and were thus classified as stage III PCs, and 34\% displayed an identified mature dendritic tree (stage IV;
Figure 1E,F). Increased concentration of $\mathrm{T}_{3}(100 \mathrm{nM})$ also led to an acceleration of the dendritic differentiation (compared to $0 \mathrm{nM}$ and $3 \mathrm{nM}$ of $\mathrm{T}_{3}$ ), although this treatment was not as efficient as $30 \mathrm{nM} \mathrm{T}_{3}$ since the proportion of stage IV PCs was lower (Figure 1G,H). Thus, these results show that, in organotypic culture, as already demonstrated for dissociated cell culture $[10,11]$, the addition of $\mathrm{T}_{3}$ to the culture medium promotes PC dendritic development in a dose-dependent manner. In the following experiments, we have used the $30 \mathrm{nM}$ concentration to assess the effects of $\mathrm{T}_{3}$ since this concentration is the most efficient in our culture conditions.

\section{$\mathrm{T}_{3}$ leads to an increased amount of ROR $\alpha$ protein in PCs and interneurons}

To determine whether the $\mathrm{T}_{3}$-induced acceleration of dendritic differentiation involves $\mathrm{ROR} \alpha$, we first assessed ROR $\alpha$ expression in cerebellar slices in response to $T_{3}$ treatment. By combination of promoter usage and alternative splicing, the Rora gene encodes two isoforms in the mouse (ROR $\alpha 1$ and ROR $\alpha 4$ ), which differ only in their amino-terminal modulator region [21-23].

Western blots of P0 7 DIV cerebellar slices were performed with antibodies directed against the carboxyl terminus of ROR $\alpha$, which can detect both ROR $\alpha 1$ and ROR $\alpha 4$ isoforms. We detected an increase of 6.8 -fold in the amount of ROR $\alpha 1$ protein in slices treated with $30 \mathrm{nM}$ of $\mathrm{T}_{3}$ (Figure 2A).

In the cerebellum, $\mathrm{ROR} \alpha$ is known to be expressed only in PCs and interneurons [24]. In order to determine in which cell type the upregulation of $\mathrm{ROR} \alpha$ expression occurs, we used immunofluorescence to detect and locate the ROR $\alpha$ protein in organotypic cultures. Since only PCs in the cerebellum express CaBP, we used $\mathrm{CaBP}$ as a PC-specific marker, and we used parvalbumin as a marker of interneurons. Both mature interneurons and PCs express parvalbumin: interneurons were unambiguously identified as parvalbumin-positive and CaBP-negative cells.

To assess whether $\mathrm{T}_{3}$ led to increased expression ROR $\alpha 1$ in PCs, we quantified the fluorescence density of ROR $\alpha$ labeling within the nucleus of PCs. We observed a significant increase in the fluorescence density in $\mathrm{T}_{3}$-treated slices compared to control $\mathrm{T}_{3^{-}}$ untreated slices (Figure 2B). Interestingly, following $\mathrm{T}_{3}$ treatment, ROR $\alpha$ labeling was observed in PCs and also in some CaBP-negative cells. Some CaBP-negative cells that express ROR $\alpha$ also expressed parvalbumin, and were thereby identified as interneurons (Figure 2B). Therefore, $\mathrm{T}_{3}$ treatment led to increased expression of ROR $\alpha$ in both PCs and parvalbumin-positive interneurons.

To determine whether the increase in ROR $\alpha$ protein levels in $\mathrm{T}_{3}$-treated cerebellar slices is the consequence of 

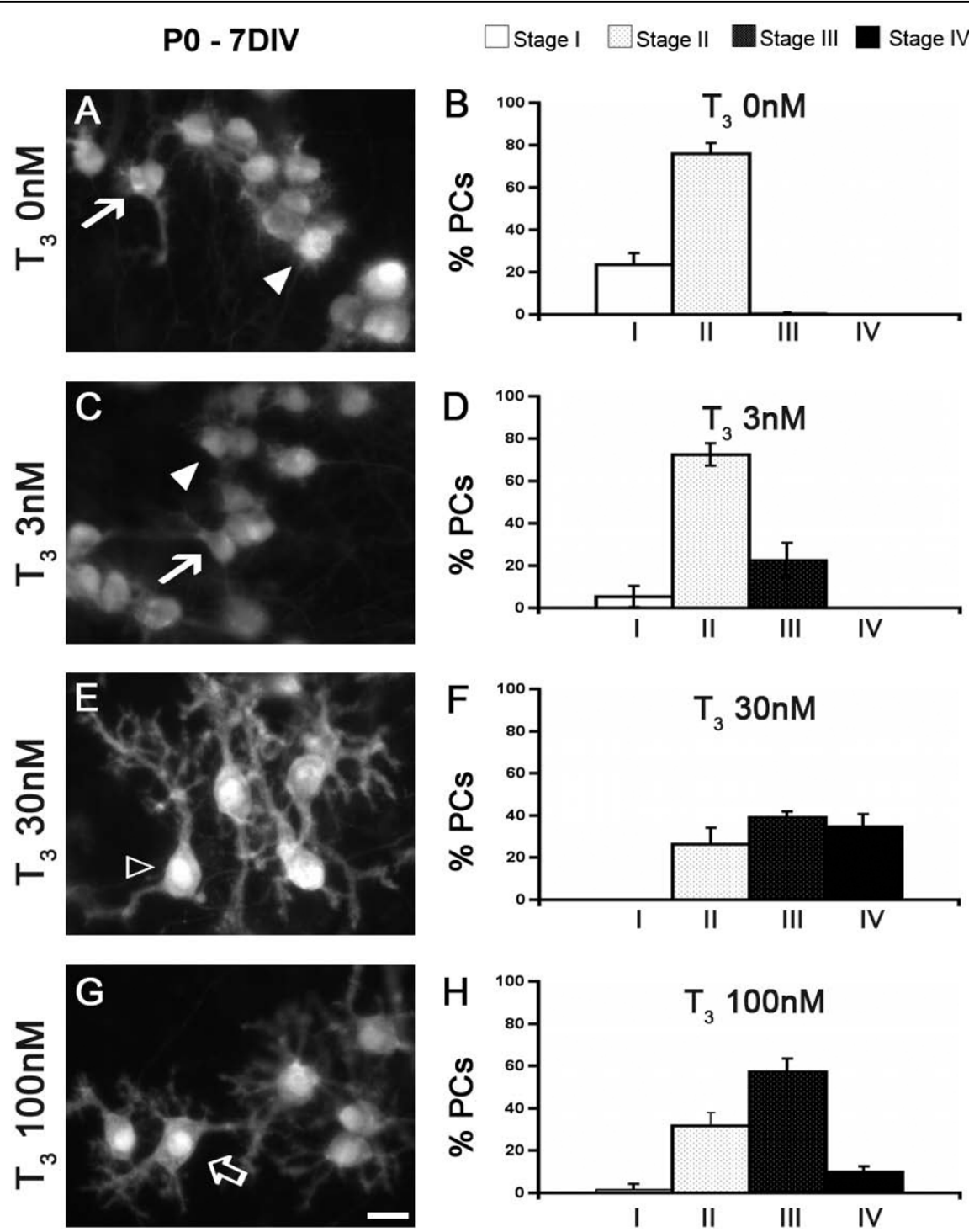

Figure 1 Dose-dependent effect of $T_{3}$ on PC dendritic differentiation in organotypic cultures. (A-H). Organotypic cultures of PO cerebella were kept 7 DIV in the absence of $T_{3}(A, B)$, or in the presence of $3 n \mathrm{nM} \mathrm{T}_{3}(C, D), 30 \mathrm{nM} T_{3}(E, F)$ or $100 \mathrm{nM} T_{3}(G, H)$. $(A, C, E, G) P C s$ were revealed by CaBP immunolabeling. $(B, D, F, H)$ Quantitative distribution of PCs between stages I to IV. Fusiform PCs with a bipolar shape are defined as stage I (arrow in $(A, C)$ ), PCs with regressive atrophic dendrites all around the soma are defined as stage II (white arrowhead in (A,C)), PCs with one or more perisomatic protrusions are defined as stage III (empty arrow in $(G)$ ) and PCs with an identified dendritic tree are classified as stage IV (empty arrowhead in (E)). Scale bar $=20 \mu \mathrm{m}$. Error bars indicate mean \pm standard deviation.

increased expression of the Rora gene, and not stabilization of the protein, we analyzed by real time RT-PCR the mRNA level of the different Rora isoforms in the $\mathrm{T}_{3}$-treated slices compared to untreated slices after 7 DIV (Figure 2C). A 3.3-fold increase was observed for Rora1 after 7 DIV. The Rora4 mRNA level was similar to untreated slices after 7 DIV. These results show that $\mathrm{T}_{3}$ leads to increased expression of the Rora1 isoform after 7 DIV.

These results show that $T_{3}$ induced increased ROR $\alpha 1$ protein levels in PCs in parallel with their dendritic differentiation after 7 DIV.
$T_{3}$ accelerates the first steps of early PC dendritic differentiation and increases Rora gene expression at PO As we previously demonstrated that ROR $\alpha$ is involved in early dendritic differentiation [12], we examined whether $\mathrm{T}_{3}$ promotes this early change. We thus assessed the effect of $\mathrm{T}_{3}$ treatment on cerebellar slices after 3 DIV, a time when PCs cultured without $\mathrm{T}_{3}$ display mainly bipolar fusiform dendritic morphology (stage I; 97\%) whereas very few are in a stellate or atrophic morphology (stage II; 3\%; Figure 3A). In the presence of $30 \mathrm{nM}$ of $\mathrm{T}_{3}$ after $3 \mathrm{DIV}$, all PCs were still 
A
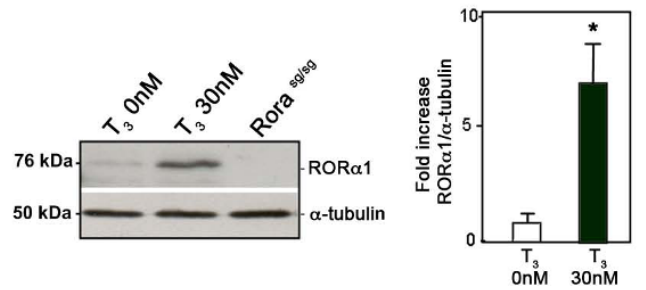

B
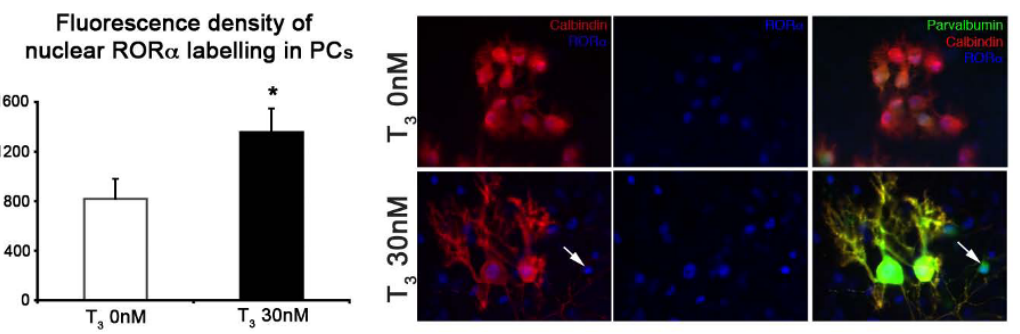

C

RORalpha1 mRNA level
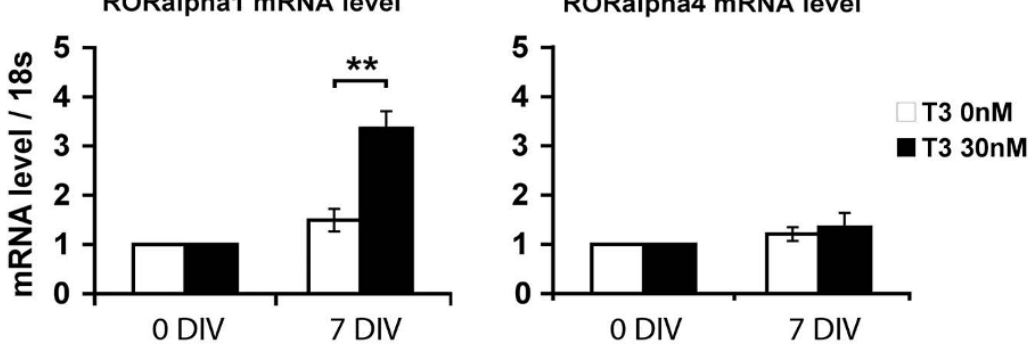

Figure $2 \mathrm{~T}_{3}$ treatment increases the amount of ROR $\boldsymbol{\alpha}$ protein and RNA in organotypic cultures. PO cerebellar slices kept for 7 DIV were cultured in the absence or the presence of $30 \mathrm{nM} \mathrm{T}_{3}$. (A) Immunoblot analysis and quantification of ROR $\alpha$ levels in extracts of untreated or $T_{3^{-}}$ treated cerebellar slices ( $\left.{ }^{*} P<0.05\right)$. (B) Left panel: fluorescence density of ROR $\alpha$ immunolabeling was measured within each PC nucleus with MetaMorph software. Average values from multiple cells \pm SEM are shown $\left.{ }^{*} P<0.05\right)$. Right panel: organotypic cultures after 10 DIV without $T_{3}$ (upper row) or with $T_{3}(30 \mathrm{nM}$ ) treatment (lower row). ROR $\alpha$-expressing cells were revealed by ROR $\alpha$ immunolabeling (blue), PCs were revealed by CaBP immunolabeling (red) and both PCs and interneurons were revealed by parvalbumin immunolabeling (green). Note the presence of ROR $\alpha$-expressing interneurons (arrow) in the $T_{3}$ only treatment. (C) PO organotypic cultures were cultured without $\mathrm{T}_{3}$ (white bars) or with $30 \mathrm{nM}$ $\mathrm{T}_{3}$ (black bars) for 7 days. Levels of mRNA were determined by real time RT-PCR and standardized to $18 \mathrm{~s}$ rRNA The data are given relative to the mRNA level in untreated slices at the initial time of the culture (0 DIV). They were obtained from three independent cerebellar slices extracts $\left({ }^{*} P<0.05 ;{ }^{*} P<0.005\right)$. Error bars in $(C)$ indicate mean \pm standard deviation.

in stage I or II, but we observed an increased number of PCs in stage II (28\%; Figure 3A) compared to the control without $\mathrm{T}_{3}$ (3\%; Figure $\left.3 \mathrm{~A}\right)$. From those experiments, we can conclude that $\mathrm{T}_{3}$ promotes the first dendritic differentiation steps of PCs from stage I to stage II in organotypic cultures.

To determine whether T3 increases Rora expression in early stages of PC development, we analyzed the mRNA levels of the Rora isoforms in response to $\mathrm{T}_{3}$ treatment during the first day of culture (Figure 3B). We observed a specific increase in the Rora1 mRNA level after $6 \mathrm{~h}$ and $24 \mathrm{~h}$ of $\mathrm{T}_{3}$ treatment (6.5- and 5.7-fold increase, respectively). The Rora 4 mRNA level was slightly and transiently increased in slices after $24 \mathrm{~h}$ of $\mathrm{T}_{3}$ treatment (1.7-fold increase). These results show that $\mathrm{T}_{3}$ leads to increased expression of the Rora1 isoform in fusiform PCs at P0 and, to a lesser extent, of the Rora4 isoform. Interestingly, our results also revealed that mRNA levels of both Rora1 and Rora4 isoforms were stable in cultures made at P0 and kept for $6 \mathrm{~h}, 24 \mathrm{~h}$ and 7 DIV in culture without $\mathrm{T}_{3}$ (compare Figures $2 \mathrm{C}$ and $3 \mathrm{~B}$ ).

\section{$\mathrm{T}_{3}$-induced early dendritic differentiation involves ROR $\alpha$}

The experiments described above show that $T_{3}$ promotes dendritic differentiation (Figures 1 and 3) and leads to increased expression of ROR $\alpha 1$ (Figures 2 and $3)$. We have recently shown that ROR $\alpha$ is a crucial factor controlling the early steps of PC dendritic differentiation, and staggerer ROR $\alpha$-deficient PCs do not progress beyond early bipolar migratory morphology 

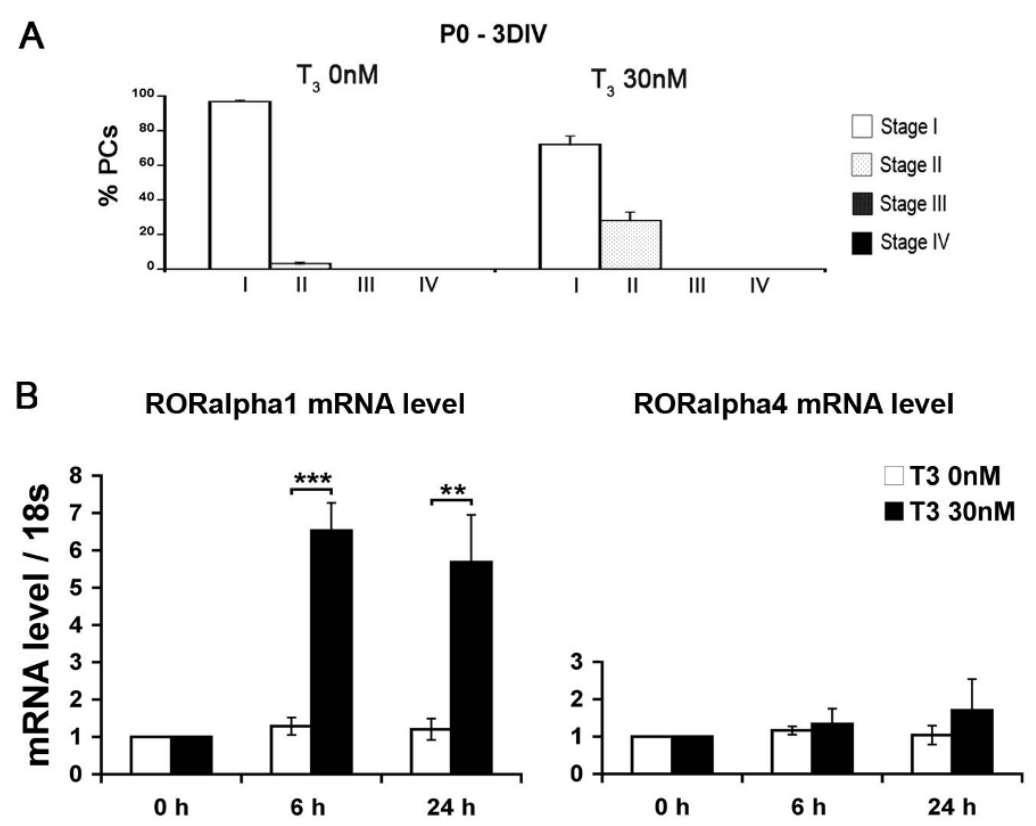

Figure $3 \mathrm{~T}_{3}$ promotes the early dendritic differentiation of PCs and leads to increased mRNA levels of Rora1 and Rora4 at P0. (A) Quantitative distribution of PCs between stages I and IV. Cultures of PO cerebella were kept 3 DIV in the absence or the presence of $30 \mathrm{nM} \mathrm{T}_{3}$. PCs are classified following the same criteria as in Figure 1. (B) P0 organotypic cultures were cultured without $T_{3}$ (white bars) or with $30 \mathrm{nM} \mathrm{T}_{3}$ (black bars). Levels of mRNA were determined by real time RT-PCR and standardized to $18 \mathrm{~s}$ rRNA after $0 \mathrm{~h}, 6 \mathrm{~h}$ or $24 \mathrm{~h}$ of $\mathrm{T}_{3}$ treatment. The data are given relative to the mRNA level in untreated slices at the initial time of the culture $(0 \mathrm{~h})$. They were obtained from three independent cerebellar slice extracts $\left({ }^{* *} P<0.005 ;{ }^{* *} P<0.0005\right)$. Error bars indicate mean \pm standard deviation.

[12]. To determine whether $\operatorname{ROR} \alpha$ is actually involved in the $\mathrm{T}_{3}$-induced $\mathrm{PC}$ dendritic differentiation, we followed the progression of the dendritic differentiation of PCs from staggerer $\left(\right.$ Rora $\left.^{s g / s g}\right)$ and corresponding control Rora $^{+/+}$cerebellar slices treated or not with $\mathrm{T}_{3}$.

As previously observed in serum-containing cultures [12], PCs from Rora ${ }^{\text {sg/sg }}$ cultured in serum-free medium display the embryonic bipolar shape (stage I) after 7 DIV (Figure 4B), whereas most PCs in control Rora $^{+/+}$ cultures display 'regressive-atrophic' dendrites (stage II; Figure 4A). In the presence of $30 \mathrm{nM} \mathrm{T}_{3}$, stage II, III and IV PCs were found (Figure 4C) with the same proportions as described in Figure 1. In contrast, PCs from Rora $^{s g / s g}$ animals still display embryonic bipolar shape (Figure 4D) with long processes characteristic of stage I PCs [12], indicating that they were not responsive to $T_{3}$ treatment and remained in the very early stage of dendritic differentiation.

The absence of a functional ROR $\alpha$ protein thus prevents $T_{3}$-induced accelerated dendritic differentiation of immature bipolar P0 PCs. This experiment shows that $\mathrm{ROR} \alpha$ is required in the $\mathrm{T}_{3}$-induced dendritic differentiation-promoting process.

$\mathrm{T}_{3}$ up-regulates the activity of the Rora promoter

To gain further insight into the mechanism by which $\mathrm{T}_{3}$ up-regulates Rora gene expression, we tested the effect of $\mathrm{T}_{3}$ on the transcriptional activity of the $\mathrm{p}(-487)$ RoraLuc construct in HepG2 cells, which shows $82.9 \%$ sequence homology with the murine sequence and has been previously used as a model to analyze the transcriptional regulation of the Rora gene [25] (Additional file 1 ). $T_{3}$ treatment resulted in a 3.6-fold increase in the activity of the $\mathrm{p}(-487)$ Rora-Luc construct compared to its basal activity in the absence of $\mathrm{T}_{3}$ (Figure 5). Plasmid pDR4-TK-Luc, which contains a thyroid receptor response element (DR4), was used as a control for the effect of $\mathrm{T}_{3}$ on transcriptional activity. As expected, the luciferase activity of pDR4-TK-Luc was strongly increased (12.1-fold) by $T_{3}$ treatment, indicating that $T_{3}$ is active under our experimental conditions.

Taken together, the results of these experiments indicate that the effect of $\mathrm{T}_{3}$ on Rora expression is, at least in part, transcriptional and that the -487 to -45 Rora promoter region is involved in this regulation.

\section{Discussion}

Our results show for the first time that $\mathrm{T}_{3}$ promotes the early steps of PC dendritic differentiation, during the phase of neurite regression that precedes the formation of the ultimate dendritic tree. Addition of $\mathrm{T}_{3}$ to the serum-free medium of P0 cerebellar slices resulted in an acceleration of the early steps of dendritic differentiation. This accelerated progression of dendritic 


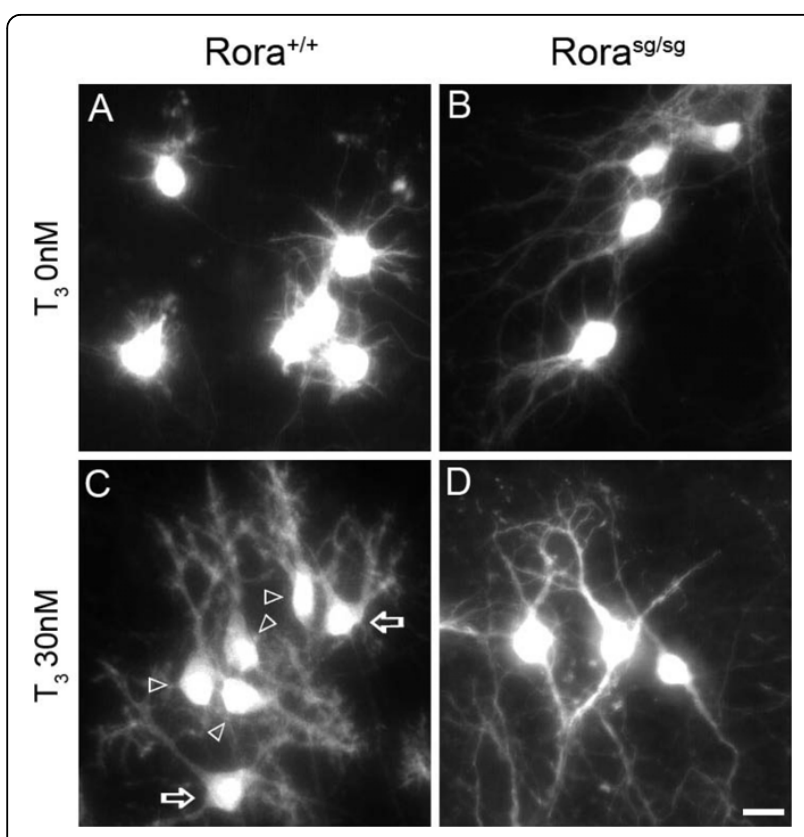

Figure $4 \mathrm{~T}_{3}$ treatment fails to induce dendritic differentiation in early RORa-deficient staggerer PCs in organotypic cultures. (A-D) PCs in organotypic cultures from wild-type $(A, C)$ or ROR $\alpha$ deficient Rora $^{5 g / s g}(\mathrm{~B}, \mathrm{D})$ PO mice were revealed by CaBP

immunolabeling after 7 DIV without $T_{3}(A, B)$ or with $30 \mathrm{nM} \mathrm{T}_{3}(C, D)$. PCs from wild-type mice responded to $T_{3}$ treatment: without $T_{3}, P C S$ were mostly in stage II (PCs with regressive-atrophic dendrites all around the soma) whereas they were in stages II, III (empty arrows) and IV (empty arrowheads) after $30 \mathrm{nM} \mathrm{T}_{3}$ treatment (C). PCs from Rora $^{59 / s g}$ mice were unresponsive to $\mathrm{T} 3$ treatment since they remain in stage I (fusiform PCs with long processes of bipolar shape) in the absence (B) or in the presence (D) of $30 \mathrm{nM} \mathrm{T}_{3}$ treatment. Note the bipolar or fusiform shape of the PCs with long processes but no dendritic arborization in $(B, D)$. Scale bar $=20 \mu \mathrm{m}$.

differentiation was accompanied by increased expression of the gene encoding the nuclear receptor ROR $\alpha$, observed at both mRNA and protein levels. We further show that the ROR $\alpha$ protein is required for the $T_{3}$ induced early dendritic differentiation, as $\mathrm{T}_{3}$ treatment did not promote dendritic differentiation in Rora $^{s g / s g}$ PCs. This result is in accordance with previous studies that suggest an unresponsiveness of $\mathrm{Rora}^{s g / s g}$ mutants to $\mathrm{TH}[19]$.

\section{$\mathrm{T}_{3}$ promotes early $\mathrm{PC}$ dendritic differentiation}

The role of $\mathrm{TH}$ in mammalian brain is well documented, particularly during cerebellar development (for review, see $[1,26])$. Congenital hypothyroidism in humans leads to a syndrome termed cretinism [27], the apparent symptoms of which include ataxia and poor motor skills, indicating cerebellar defects. In PCs, TH is known to strongly promote differentiation of the elaborate dendritic tree and synapse formation. In contrast, little is known about its role in the events preceding the

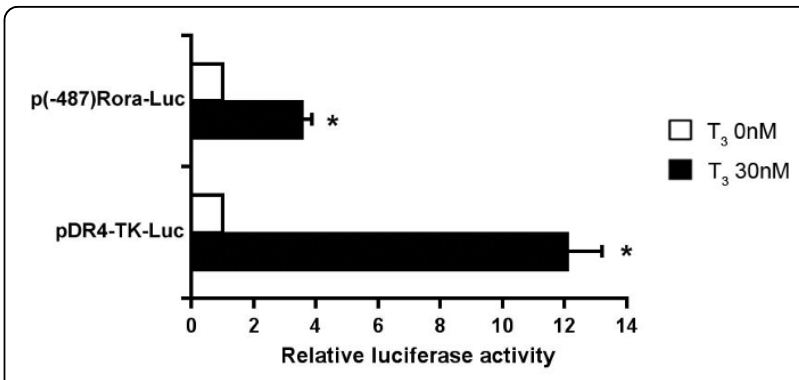

Figure $5 \mathrm{~T}_{3}$ treatment upregulates Rora promoter activity HepG2 cells cultured in 12-well plates were co-transfected with $500 \mathrm{ng} /$ well of the pTR $\alpha$ vector, allowing expression of the TR, and $500 \mathrm{ng} /$ well of the $\mathrm{p}(-487)$ Rora-Luc reporter vector, which allows expression of the luciferase gene under the control of the human genomic sequences between nucleotides -487 and -45 from the Rora1 translation initiation site, or with $500 \mathrm{ng} /$ well of the promoterless pGL3-Luc vector. HepG2 cells co-transfected with $500 \mathrm{ng} /$ well of the pTR $\alpha$ vector and of the pDR4-TK-Luc reporter vector were used as a control of the transcriptional effect of $\mathrm{T}_{3}$ on a $\mathrm{TH}$ response element. The luciferase activity of $p(-487)$ Rora-Luc and pDR4-Luc in the absence or the presence of $T_{3}(30 \mathrm{nM})$ is expressed relative to that of the promoter-less $\mathrm{PGL} 3$-Luc vector $\left({ }^{*} P<0.05\right)$. Error bars indicate mean \pm standard deviation.

development of the ultimate dendritic tree, in particular the steps of neuritic regression and early extension of perisomatic protrusions, occurring in vivo in the rodent between $\mathrm{P} 0$ and $\mathrm{P} 7$.

To better understand the effect of $\mathrm{TH}$ action in the developing brain, the temporal patterns of initiation and cessation of hormone action need to be determined. Most in vitro or in vivo experiments explore the effects of hypo- or hyperthyroidism in the cerebellum from $\mathrm{P} 15$, or its equivalent age in culture. At this age, the characteristic shape of the dendritic arborization is already achieved, and extrinsic factors such as electrical activity [28] from granule cells, trophic factors [29-32] and $\mathrm{TH}$ modulate the growth of the dendritic arborization [4]. Studies have shown a role for $\mathrm{TH}$ in the persistence of the external granular layer and the migration of granule cells into the internal granular layer [4,5,33], in the proliferation and differentiation of interneurons [34], as well as a direct role of $\mathrm{TH}$ on PCs through TR $\alpha 1$ receptor activation [10]. However, the effects of $\mathrm{TH}$ on PC dendritic differentiation during early steps that do not require cell-cell interaction have not been shown.

Using P0 slices after 3 DIV, we could specifically assess the role of $\mathrm{TH}$ in early development, and our results show that $T_{3}$ also plays a key role in the early dendritic differentiation of PCs in organotypic cultures, that is, before the formation of the elaborated dendritic tree. These data extend the well-known role of $\mathrm{T}_{3}$ in the later stages of PC dendritic differentiation [6,8-10] and identify a third molecule besides ROR $\alpha$ and SCLIP $[12,35]$ involved in the first steps of PC dendritic 
differentiation. Interestingly, T3 is the first extrinsic factor described to play a role in these processes.

We also show that $\mathrm{T}_{3}$ promotes the expression of both ROR $\alpha$ and parvalbumin in interneurons, which corroborates recent results from Manzano et al. [34], who have shown that $\mathrm{TH}$ acts on the proliferation and differentiation of interneuron precursors in the cerebellum [34]. Further studies will be required to determine whether the $\mathrm{TH}$ action on interneurons is mediated by ROR $\alpha$.

\section{Cross-talk between ROR $\alpha$ and the TH pathway}

Interestingly, $\mathrm{T}_{3}$ addition led to increased expression of ROR $\alpha$ in the cerebellar PCs and interneurons. This result is in accordance with previous studies that showed decreased expression of ROR $\alpha$ in the cerebellum of hypothyroid rats [36], whereas $\mathrm{T}_{4}$ replacement led to increased expression [17].

Our results indicate that $\mathrm{ROR} \alpha 1$ expression is required for the $\mathrm{T}_{3}$-induced effect on early dendritic differentiation. Further, we show that the activity of the Rora promoter was enhanced by $\mathrm{T}_{3}$ treatment in culture, suggesting that $\mathrm{TH}$ acts on the process of early dendritic differentiation through increased expression of the Rora gene. TH binds to the nuclear $\mathrm{TH}$ receptor (TR), a ligand-regulated transcription factor, which then binds to a target DNA sequence known as a $\mathrm{TH}$ response element (TRE) within the promoter region of target genes. Further studies are needed to determine whether $R O R \alpha$ is a target gene of TR, and whether the transcriptional effect observed in our study is under direct control. An additional level of interaction between ROR $\alpha$ and TR has been demonstrated by Koibuchi and collaborators [37,38], who showed that ROR $\alpha 1$ increases TR-induced transactivation on several TREs. This could account for the ROR $\alpha$ requirement in the $T_{3}$-mediated promotion of PC dendritic differentiation observed in this study. TR binds as a monomer, homodimer, or heterodimer (particularly with retinoid $\times$ receptors) to the TRE, which is composed of two half-site core motifs (AGGTCA) with specific nucleotide spacing and orientation. ROR $\alpha$ binds as a monomer to a consensus motif composed of a 6-bp AT-rich sequence 5 ' to a half-site core motif, AGGTCA (ROR-response element, RORE), to activate transcription [23]. Both TR and ROR $\alpha$ are thus transcription factors that share the common core motif within their response elements. ROR $\alpha 1$ is able to bind as a monomer to one of two core motifs (AGGTCA) of a TRE that is preceded by an AT-rich sequence [23,37]. This suggests that a subset of natural TREs containing appropriate AT-rich sequences could serve as dual-response elements for TR and ROR $\alpha$. Because of the high homology between the human and murine ROR $\alpha 1$ coding and promoter sequences, it is possible that $R O R \alpha$ mediates some $\mathrm{TH}$ actions in human. Beside its roles in the developing cerebellum, ROR $\alpha$ has also been shown to play critical roles in many different tissues and systems, including immunity, cancer, cellular metabolism, circadian rhythm, development and ageing (for review, see [39]). Understanding the roles of ROR $\alpha$ could therefore provide further information about the pleiotropic effects of late prenatal or early postnatal hypo- and hyperthyroidism in humans.

Intrinsic effect of $\mathrm{ROR} \alpha$, and potential coordination with $\mathrm{TH}$ in the $\mathrm{PC}$ dendritic differentiation process

ROR $\alpha$ has been shown to be crucial for the progression of early differentiation of PCs in a cell-autonomous manner [12]. In cerebellar slices, $\mathrm{T}_{3}$ is likely to act on ROR $\alpha$ expression within PCs. Our results extend previous studies of Heuer and Mason [10], which clearly demonstrated that PCs are a direct target of $\mathrm{TH}$ action through activation of $\mathrm{TR} \alpha 1$ : $\mathrm{TH}$ promotes the late stages of the elaboration of PC dendritic arborization, which is also dependent upon granule cell differentiation and synaptogenesis. Interestingly, ROR $\alpha$ has been shown to control the expression of Sonic hedgehog (Shh) in PCs, which in turn promotes the proliferation of granule cells precursors in the external granular layer [40]. Thus, a coordinate mechanism involving $\mathrm{ROR} \alpha$ and $\mathrm{TH}$ in cerebellar development can be proposed in which both $\mathrm{T}_{3}$ and $\mathrm{ROR} \alpha$ act on PC dendritic differentiation directly as well as indirectly via the promoting effect on granule cell development. However, the later and direct effects of $\mathrm{T}_{3}$ on early PC differentiation are unlikely to be mediated by ROR $\alpha$ since we have shown that ROR $\alpha$ does not influence this later step of differentiation [12].

In its homozygous state, the murine staggerer mutation of the Rora gene leads to cerebellar atrophy due to the degeneration of most PCs [13,15,41-43]. Several histological studies of the $\mathrm{Rora}^{s g / s g}$ cerebellum show that the remaining PCs are immature and display atrophic dendrites, devoid of spines [44-46]. These abnormalities of dendritic differentiation observed in homozygous staggerer mice are similar to, but worse than, those observed in hypothyroid rats. This implies that ROR $\alpha$ acts on additional processes in cerebellar development, apart from those induced by THs. This hypothesis is strengthened by the recently demonstrated neuroprotective role of ROR $\alpha$ at least partly through its control of oxidative stress mechanisms [16,47].

In conclusion, our results show that ROR $\alpha$ plays a critical role in the early $\mathrm{T}_{3}$-induced dendritic differentiation of PCs.

\section{Materials and methods \\ Animals}

Animal housing and all procedures were carried out in accordance with the guidelines of the French Ministry 
of Agriculture and the European Community. Swiss mice were obtained from Janvier (Le Genest-St-Isle, France). The staggerer Rora ${ }^{\text {sg/sg }}$ mutant mice were maintained on a C57BL/6J genetic background in our colony. Rora $^{\text {sg/sg }}$ and their Rora $^{+/+}$littermates were obtained by intercrossing fertile heterozygous $\mathrm{Rora}^{+/ s g}$ animals, and were genotyped by PCR, as previously described [12].

\section{Organotypic slice cultures}

Swiss mice at P0 were used. Organotypic cultures of cerebellum were prepared as described previously [48]. Briefly, after decapitation, brains were dissected out into cold Gey's balanced salt solution (Sigma, Lyon, France) supplemented with $5 \mathrm{mg} / \mathrm{ml}$ glucose, and the meninges were removed. Parasagittal cerebellar slices $(350 \mu \mathrm{m}$ thick) were cut on a McIlwain tissue chopper (Stoetling Europe, Dublin, Ireland) and transferred onto $30 \mathrm{~mm}$ Millipore membrane culture inserts with a $0.4 \mu \mathrm{m}$ pore size (Millicell CM, Millipore, Molsheim, France). Slices were maintained in culture in six-well plates containing $1 \mathrm{ml}$ per well of medium containing basal medium with Earle's salts (BME), supplemented with Sigma I-1884 supplement (1:100 dilution, resulting in final concentrations of $5 \mu \mathrm{g} / \mathrm{ml}$ insulin, $5 \mu \mathrm{g} / \mathrm{ml}$ transferrin, and $5 \mathrm{ng} / \mathrm{ml}$ sodium selenite), $0.5 \mu \mathrm{g} / \mathrm{ml}$ BSA (Sigma), $4 \mathrm{mM}$ L-glutamine (Invitrogen, GIBCO, Cergy Pontoise, France), $5 \mathrm{mg} / \mathrm{ml}$ glucose, with or without $\mathrm{T}_{3}$ at $37^{\circ} \mathrm{C}$ in a humidified atmosphere with $5 \% \mathrm{CO}_{2}$. The medium was replaced every 2 days (after 2, 4 and 6 days in culture).

Mice obtained from Rora $^{+/ s g}$ intercrosses were also used in this study. In these litters, Rora $^{+/+}$, Rora $^{+/ s g}$ and Rora $^{s g / s g}$ mice could be generated. For each animal, slices of each cerebellum were divided between two Millicells: half of the cerebellar slices served as controls and no $\mathrm{T}_{3}$ was added and the other half were treated with $\mathrm{T}_{3}(30 \mathrm{nM})$ in order to compare control $(0 \mathrm{nM} \mathrm{T})$ versus $\mathrm{T}_{3}$-treated slices (30 $\mathrm{nM} \mathrm{T}_{3}$ ) from the same animals. The genotype was determined $a$ posteriori by PCR on tail biopsy, in blind studies.

\section{Antibodies and staining procedures}

Immunostaining of CaBP, parvalbumin or ROR $\alpha$ was performed as described previously [12]. Briefly, cerebellar slices were fixed in $4 \%$ paraformaldehyde, and then incubated for $1 \mathrm{~h}$ in phosphate-buffered saline containing $0.25 \%$ Triton $\mathrm{X}-100,0.2 \%$ gelatin, $0.1 \%$ sodium azide (PBSGTA) and 0.1 M lysine. Rabbit polyclonal or mouse anti-CaBP antibody (1:5,000 dilution; Swant, Switzerland) to visualize PCs, or rabbit polyclonal anti-parvalbumin (1:5,000 dilution; Swant) to visualize both PCs and interneurons, and goat polyclonal anti-ROR $\alpha 1$ (sc-6062; 1:4,000 dilution; Santa-Cruz, Tebu-Bio SA, Le Perray en Yvelines, France) in PBSGTA were applied overnight. At this dilution, the intensity of $\mathrm{ROR} \alpha$ labeling was correlated to the ROR $\alpha$ expression level [12]. Specific labeling was detected with $\mathrm{Cy} 3$-conjugated donkey anti-rabbit antibody (1:500 dilution; Jackson Immunoresearch, Immunotech, Marseille, France) and FITCconjugated donkey anti-goat antibody (1:2,000 dilution; Jackson Immunoresearch). The slices were analyzed with an inverted microscope (Nikon Eclipse TE 300). Immunofluorescence images were captured at $400 \times$ magnification using a Qimaging Retiga 1300 camera, and analyzed using Image-Pro Plus 4.1 software (Media Cybernetics, Bethesda, MD, USA). For ROR $\alpha$ fluorescence intensity measurements, fluorescence density was measured in the nucleus of PCs (visualized by CaBP immunolabeling) using MetaMorph software.

\section{Classification of PC dendritic differentiation stages}

Classification of PCs was assessed after $\mathrm{CaBP}$ immunostaining, as previously described [12]. Briefly, fusiform PCs with a bipolar shape, reminiscent of embryonic migratory PCs, are defined as stage I and correspond to both 'simple' and 'complex' fusiform stages, observed from embryonic day 16 to P4 in vivo [20]. Stage II comprises PCs with short processes all around the soma. This 'stellate' stage includes both 'regressive-atrophic dendrites' and 'stellate cell' stages described previously, from P2 to P6 in vivo. PCs with more than one long and mature dendritic protrusion are defined as stage III. They correspond to PCs around P5 to P10 in vivo. Finally, PCs with one well identified dendritic tree (defined as primary dendrites giving rise to additional side branches) are classified as stage IV. Images were taken from all slices, corresponding to at least 200 PCs in each experiment. Quantification was performed on three independent experiments.

\section{Western-blot analysis}

Cultured slices were lysed in solubilization buffer (500 mM NaCl, $1 \mathrm{mM} \mathrm{MgCl}_{2}, 2 \mathrm{mM}$ EGTA, $50 \mathrm{mM}$ Bicine, $\mathrm{pH}$ 9.0, $50 \mathrm{mM} \mathrm{NaF}, 5 \mu \mathrm{M} \mathrm{ZnCl}, 100 \mu \mathrm{M}$ $\mathrm{Na}_{3} \mathrm{VO}_{4}, 1 \mathrm{mM}$ dithiothreitol, $5 \mathrm{nM}$ okadaic acid, 2.5 $\mu \mathrm{g} / \mathrm{ml}$ aprotinin, $3.6 \mu \mathrm{M}$ pepstatin, $0.5 \mu \mathrm{M}$ phenylmethylsulfonyl fluoride, $0.5 \mathrm{mM}$ benzamidine, $5.3 \mu \mathrm{M}$ leupeptin) and dounced at $4^{\circ} \mathrm{C}$. Insoluble materials were removed by centrifugation $(13,000 \mathrm{~g}$ for 20 minutes at $4^{\circ} \mathrm{C}$ ), supernatants were isolated and the samples were stored at $-80^{\circ} \mathrm{C}$. Proteins were dosed with the DC protein assay kit (Bio-Rad, Hercules, CA, USA). As previously described [49], cell-extracts containing equivalent amounts of protein were boiled for 5 minutes in sample loading buffer. After a $10 \%$ SDS-PAGE, proteins were transferred to a polyvinylidene difluoride membrane (ICN Biochemicals, Costa Mesa, CA USA). Non-specific sites were blocked with $5 \%$ skimmed dried 
milk for $2 \mathrm{~h}$. Blots were then incubated overnight at $4^{\circ} \mathrm{C}$ with primary antibodies against ROR $\alpha$ (1:2,000; Santa Cruz) and $\alpha$-tubulin (1:10,000; Sigma) in 5\% skimmed dried milk. They were then incubated with horseradish peroxidase-conjugated secondary antibodies in 5\% skimmed dried milk for $1 \mathrm{~h}$. The revelation was processed with enhanced chemoluminescence substrate (Amersham, Saclay. France). Quantification was performed using Densylab software (Microvision Instruments, Evry, France).

\section{Real-time RT-PCR}

Total RNA from cerebellar slices from three animals was prepared according to the manufacturer's instructions using the RNeasy kit (Qiagen, Courtaboeuf, France) and cDNAs were synthesized from $1 \mu \mathrm{g}$ of RNA (Promega, Charbonnieres-les-Bains, France) and avian myeloblastosis virus (AMV) reverse transcriptase, as per the manufacturer's instructions.

RT-PCR was performed using the ABsolute ${ }^{\mathrm{TM}}$ QPCR $\mathrm{SYBR}^{\odot}$ Green Mixes Kit (ABgene, Courtabeoeuf, France), as per the manufacturer's instructions. Reactions were performed in $25 \mu \mathrm{l}$ of total volume containing ABsolute $^{\mathrm{TM}}$ QPCR SYBR ${ }^{\odot}$ Green Mix with $8 \mathrm{ng}$ of the first-strand cDNA and $300 \mathrm{nM}$ of primers. The following primers were used: Rora1 sense, 5'-AGGCAGAGCTATGCGAGC-3', and antisense, 5'TCAAACAGTTCTTCTGACGAGG-3'; Rora4 sense, 5'-GTCACATGGAGCC TCTTATGG-3', and antisense, 5'-TCAAACAGTT CTTCTGACGAGG-3'; $18 \mathrm{~s}$ sense, 5'-GGGAGCCTGAGAAACGGC-3', and antisense, 5' GGGTCGGA GTGGGTAATTT-3'. Amplification was performed on an iCycler (Bio-Rad) according to the manufacturer's instructions and cycle parameters were: $50^{\circ} \mathrm{C}$ (2 minutes) and $95^{\circ} \mathrm{C}(10 \mathrm{~min}$ utes), followed by 40 cycles of $95^{\circ} \mathrm{C}(15 \mathrm{~s}), 60^{\circ} \mathrm{C}(30 \mathrm{~s})$ and $72^{\circ} \mathrm{C}(30 \mathrm{~s})$. For expression quantification, a comparative $C_{\mathrm{T}}$ method was used [50,51]. The $\Delta C_{\mathrm{T}}$ value was obtained by subtracting the $C_{\mathrm{T}}$ value of the $18 \mathrm{~S}$ (reference) from the $C_{\mathrm{T}}$ value of the gene of interest, where in each case the mean value of three reactions was used. For each gene, the fold change was calculated according to the formula $2\left(C_{\mathrm{T}}\right)$, where $\Delta \Delta C_{\mathrm{T}}$ was the difference between the $\Delta C_{\mathrm{T}}$ of T3-treated cultures and the $\Delta C_{\mathrm{T}}$ of untreated cultures as a calibrator value. To distinguish specific amplicons from non-specific amplifications, a dissociation curve was generated for each transcript. Quantification was performed on three independent experiments.

\section{Vectors, transient transfection and luciferase assay}

The plasmid $\mathrm{p}(-487)$ Rora-Luc contains the luciferase reporter gene placed under the control of the promoter region of the human Rora gene, from -487 to -45 relative to the Rora translation initiation site [25]. The vector $\mathrm{pTR} \alpha$, containing mouse TR $\alpha 1 \mathrm{cDNA}$, cloned in plasmid pSG5 and plasmid pDR4-TK-Luc, which contains a TRE in front of the promoter of the thymidine kinase gene of the herpes simplex virus controlling expression of the luciferase gene where kind gifts of Dr F Flamand (Ecole Normale Superieure, Lyon, France).

The promoter-less pGL3-basic luciferase reporter vector (pGL3-Luc) was from Promega. Transient transfection experiments were done with HepG2 human hepatoma cells using the calcium phosphate method. Twenty-four hours after the transfection, $30 \mathrm{nM}$ of $\mathrm{T}_{3}$ were added to the medium and the luciferase activity was assayed $24 \mathrm{~h}$ later, as described [25]. Activities corresponding to cells cultured with $30 \mathrm{nM}$ of $\mathrm{T}_{3}$ were expressed relative to those of control cells cultured without $\mathrm{T}_{3}$.

\section{Statistical analysis}

Independent experiments were performed with 10 to 12 cerebellar slices per sample and repeated three times using matched controls. For PC stage quantification, at least 200 PCs were analyzed in each sample. For the ROR $\alpha$ RNA level quantification by real-time PCR, all slices of three animals were used in each experiment. Results are expressed in Figures as mean \pm standard deviation. The statistical significance of differences between control and $\mathrm{T}_{3}$-treated slices was assessed by a Student's $t$-test using Statview software (SAS Institute Inc., Berkeley, CA, USA).

\section{Additional material}

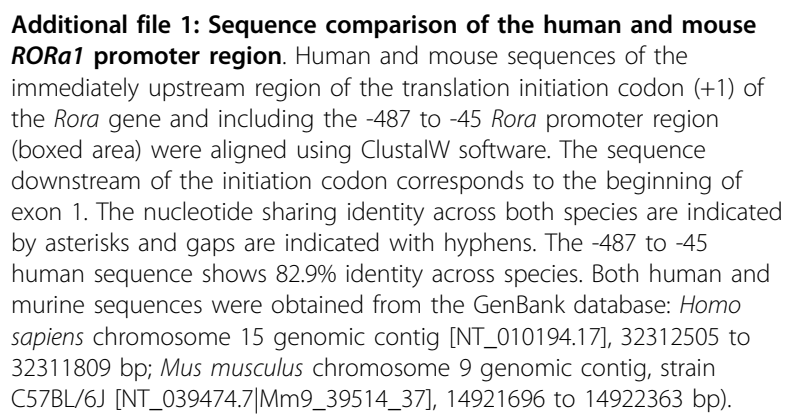

\section{Abbreviations}

bp: base pair; CaBP: calbindin; DIV: days in vitro; P: postnatal day; PC: Purkinje cell; ROR $\alpha$ : Retinoic acid receptor-related orphan receptor alpha; sg: staggerer; $T_{3}$ : L-3,3',5-triiodothyronine; TH: thyroid hormone; TR: thyroid hormone receptor; TRE: TH response element.

\section{Acknowledgements}

This research was supported by grants from Fondation pour la Recherche Médicale (FB), Fondation Lejeune (FB) and ANR-07-NEURO-043-01 (ID). We thank Rachel Sherrard for helping us with the manuscript. 


\section{Author details}

${ }^{1}$ UPMC Université Paris 6, UMR 7102 NPA, F-75005, Paris, France. ${ }^{2}$ CNRS, UMR 7102 NPA, F-75005, Paris, France. ${ }^{3}$ Biozentrum, Department of Cell Biology, University of Basel, CH-4056 Basel, Switzerland. ${ }^{4}$ Faculté de Médecine Paris Descartes, site Necker, FRE CNRS 3210, F-75015, Paris, France. ${ }^{5}$ Hôpital Charles Foix, UEF, F-94205, Ivry-sur-Seine, France.

\section{Authors' contributions}

FB conceived of the study, designed and conducted experiments, and wrote the manuscript. RW and BBJ contributed to experiments; BB contributed to experiments and helped edit the manuscript. JLD, ID and JM supervised the study, and participated in its design and coordination, and helped edit the manuscript.

\section{Competing interests}

The authors declare that they have no competing interests.

Received: 25 April 2010 Accepted: 27 July 2010 Published: 27 July 2010

\section{References}

1. Oppenheimer JH, Schwartz HL: Molecular basis of thyroid hormonedependent brain development. Endocr Rev 1997, 18:462-475.

2. Anderson GW: Thyroid hormones and the brain. Front Neuroendocrinol 2001, 22:1-17.

3. Nicholson JL, Altman J: Synaptogenesis in the rat cerebellum: effects of early hypo- and hyperthyroidism. Science 1972, 176:530-532.

4. Nicholson JL, Altman J: The effects of early hypo- and hyperthyroidism on the development of rat cerebellar cortex. I. Cell proliferation and differentiation. Brain Res 1972, 44:13-23.

5. Nicholson JL, Altman J: The effects of early hypo- and hyperthyroidism on the development of the rat cerebellar cortex. II. Synaptogenesis in the molecular layer. Brain Res 1972, 44:25-36.

6. Vincent J, Legrand C, Rabie A, Legrand J: Effects of thyroid hormone on synaptogenesis in the molecular layer of the developing rat cerebellum. J Physiol (Paris) 1982, 78:729-738.

7. Crepel F: Excitatory and inhibitory processes acting upon cerebellar Purkinje cells during maturation in the rat; influence of hypothyroidism. Exp Brain Res 1974, 20:403-420.

8. Koibuchi N: The role of thyroid hormone on cerebellar development. Cerebellum 2008, 7:530-533.

9. Kimura-Kuroda J, Nagata I, Negishi-Kato M, Kuroda Y: Thyroid hormonedependent development of mouse cerebellar Purkinje cells in vitro. Brain Res Dev Brain Res 2002, 137:55-65.

10. Heuer $H$, Mason CA: Thyroid hormone induces cerebellar Purkinje cell dendritic development via the thyroid hormone receptor alpha1. J Neurosci 2003, 23:10604-10612.

11. Sotelo C, Dusart I: Intrinsic versus extrinsic determinants during the development of Purkinje cell dendrites. Neuroscience 2009, 162:589-600.

12. Boukhtouche F, Janmaat S, Vodjdani G, Gautheron V, Mallet J, Dusart I, Mariani J: Retinoid-related orphan receptor alpha controls the early steps of Purkinje cell dendritic differentiation. J Neurosci 2006, 26:1531-1538.

13. Sidman RL, Lane PV, Dickie MM: staggerer, a new mutation in the mouse affecting the cerebellum. Science 1962, 136:610-612

14. Hamilton BA, Frankel WN, Kerrebrock AW, Hawkins TL, FitzHugh W, Kusumi K, Russell LB, Mueller KL, van Berkel V, Birren BW, Kruglyak L, Lander ES: Disruption of the nuclear hormone receptor RORalpha in staggerer mice. Nature 1996, 379:736-739.

15. Doulazmi M, Frederic F, Capone F, Becker-Andre M, Delhaye-Bouchaud N, Mariani J: A comparative study of Purkinje cells in two RORalpha gene mutant mice: staggerer and RORalpha(-/-). Brain Res Dev Brain Res 2001, 127:165-174

16. Boukhtouche F, Doulazmi M, Frederic F, Dusart I, Brugg B, Mariani J: RORalpha, a pivotal nuclear receptor for Purkinje neuron survival and differentiation: from development to ageing. Cerebellum 2006, 5:97-104.

17. Koibuchi N, Chin WW: ROR alpha gene expression in the perinatal rat cerebellum: ontogeny and thyroid hormone regulation. Endocrinology 1998, 139:2335-2341

18. Messer A, Hatch K: Persistence of cerebellar thymidine kinase in staggerer and hypothyroid mutants. J Neurogenet 1984, 1:239-248.

19. Messer $A$ : Thyroxine injections do not cause premature induction of thymidine kinase in sg/sg mice. J Neurochem 1988, 51:888-891.
20. Armengol JA, Sotelo C: Early dendritic development of Purkinje cells in the rat cerebellum. A light and electron microscopic study using axonal tracing in 'in vitro' slices. Brain Res Dev Brain Res 1991, 64:95-114.

21. Becker-Andre $M, A n d r e ~ E$, DeLamarter JF: Identification of nuclear receptor mRNAs by RT-PCR amplification of conserved zinc-finger motif sequences. Biochem Biophys Res Commun 1993, 194:1371-1379.

22. Carlberg C, Hooft van Huijsduijnen R, Staple JK, DeLamarter JF, BeckerAndre M: RZRs, a new family of retinoid-related orphan receptors that function as both monomers and homodimers. Mol Endocrinol 1994 , 8:757-770

23. Giguere V, Tini M, Flock G, Ong E, Evans RM, Otulakowski G: Isoformspecific amino-terminal domains dictate DNA-binding properties of ROR alpha, a novel family of orphan hormone nuclear receptors. Genes Dev 1994, 8:538-553.

24. Ino H: Immunohistochemical characterization of the orphan nuclear receptor ROR alpha in the mouse nervous system. J Histochem Cytochem 2004, 52:311-323.

25. Chauvet C, Bois-Joyeux B, Berra E, Pouyssegur J, Danan JL: The gene encoding human retinoic acid-receptor-related orphan receptor alpha is a target for hypoxia-inducible factor 1. Biochem J 2004, 384:79-85.

26. Thompson CC, Potter GB: Thyroid hormone action in neural development. Cereb Cortex 2000, 10:939-945.

27. Porterfield SP, Hendrich CE: The role of thyroid hormones in prenatal and neonatal neurological development-current perspectives. Endocr Rev 1993, 14:94-106.

28. Schilling K, Dickinson MH, Connor JA, Morgan Jl: Electrical activity in cerebellar cultures determines Purkinje cell dendritic growth patterns. Neuron 1991, 7:891-902.

29. Lindholm D, Castren E, Tsoulfas P, Kolbeck R, Berzaghi Mda P, Leingartner A Heisenberg CP, Tessarollo L, Parada LF, Thoenen H: Neurotrophin-3 induced by tri-iodothyronine in cerebellar granule cells promotes Purkinje cell differentiation. J Cell Biol 1993, 122:443-450

30. Mount HT, Dean DO, Alberch J, Dreyfus CF, Black IB: Glial cell line-derived neurotrophic factor promotes the survival and morphologic differentiation of Purkinje cells. Proc Natl Acad Sci USA 1995, 92:9092-9096.

31. Hirai $H$, Launey $T$ : The regulatory connection between the activity of granule cell NMDA receptors and dendritic differentiation of cerebellar Purkinje cells. J Neurosci 2000, 20:5217-5224.

32. Swinny JD, Metzger F, J IJ-P, Gounko NV, Gramsbergen A, van der Want JJ: Corticotropin-releasing factor and urocortin differentially modulate rat Purkinje cell dendritic outgrowth and differentiation in vitro. Eur $J$ Neurosci 2004, 19:1749-1758.

33. Rabie A, Legrand J: Effects of thyroid hormone and undernourishment on the amount of synaptosomal fraction in the cerebellum of the young rat. Brain Res 1973, 61:267-278.

34. Manzano J, Cuadrado M, Morte B, Bernal J: Influence of thyroid hormone and thyroid hormone receptors in the generation of cerebellar gammaaminobutyric acid-ergic interneurons from precursor cells. Endocrinology 2007, 148:5746-5751.

35. Poulain FE, Chauvin S, Wehrle R, Desclaux M, Mallet J, Vodjdani G, Dusart I Sobel A: SCLIP is crucial for the formation and development of the Purkinje cell dendritic arbor. J Neurosci 2008, 28:7387-7398.

36. Koibuchi N, Yamaoka S, Chin WW: Effect of altered thyroid status on neurotrophin gene expression during postnatal development of the mouse cerebellum. Thyroid 2001, 11:205-210.

37. Koibuchi N, Liu Y, Fukuda H, Takeshita A, Yen PM, Chin WW: ROR alpha augments thyroid hormone receptor-mediated transcriptional activation. Endocrinology 1999, 140:1356-1364.

38. Qiu CH, Shimokawa N, Iwasaki T, Parhar IS, Koibuchi N: Alteration of cerebellar neurotropin messenger ribonucleic acids and the lack of thyroid hormone receptor augmentation by staggerer-type retinoic acid receptor-related orphan receptor-alpha mutation. Endocrinology 2007, 148:1745-1753.

39. Jetten AM: Retinoid-related orphan receptors (RORs): critical roles in development, immunity, circadian rhythm, and cellular metabolism. Nuc Recept Signal 2009, 7:e003.

40. Gold DA, Baek SH, Schork NJ, Rose DW, Larsen DD, Sachs BD, Rosenfeld MG, Hamilton BA: RORalpha coordinates reciprocal signaling in cerebellar development through Sonic hedgehog and calciumdependent pathways. Neuron 2003, 40:1119-1131. 
41. Sotelo C, Changeux JP: Transsynaptic degeneration 'en cascade' in the cerebellar cortex of staggerer mutant mice. Brain Res 1974, 67:519-526.

42. Herrup K: Role of staggerer gene in determining cell number in cerebellar cortex. I. Granule cell death is an indirect consequence of staggerer gene action. Brain Res 1983, 313:267-274.

43. Vogel MW, Sinclair M, Qiu D, Fan H: Purkinje cell fate in staggerer mutants: agenesis versus cell death. J Neurobiol 2000, 42:323-337.

44. Bradley $P$, Berry M: The Purkinje cell dendritic tree in mutant mouse cerebellum. A quantitative Golgi study of Weaver and Staggerer mice. Brain Res 1978, 142:135-141.

45. Sotelo C, Privat A: Synaptic remodeling of the cerebellar circuitry in mutant mice and experimental cerebellar malformations. Study "in vivo" and "in vitro". Acta Neuropathol (Berl) 1978, 43:19-34.

46. Sotelo C: Cerebellar synaptogenesis: what we can learn from mutant mice. J Exp Biol 1990, 153:225-249.

47. Boukhtouche F, Vodjdani G, Jarvis Cl, Bakouche J, Staels B, Mallet J, Mariani J, Lemaigre-Dubreuil Y, Brugg B: Human retinoic acid receptorrelated orphan receptor alpha1 overexpression protects neurones against oxidative stress-induced apoptosis. J Neurochem 2006, 96:1778-1789.

48. Ghoumari AM, Wehrle R, De Zeeuw Cl, Sotelo C, Dusart I: Inhibition of protein kinase $\mathrm{C}$ prevents Purkinje cell death but does not affect axonal regeneration. J Neurosci 2002, 22:3531-3542.

49. Duplus E, Gras C, Soubeyre V, Vodjdani G, Lemaigre-Dubreuil Y, Brugg B: Phosphorylation and transcriptional activity regulation of retinoidrelated orphan receptor alpha 1 by protein kinases C. J Neurochem 2008, 104:1321-1332

50. Aarskog NK, Vedeler CA: Real-time quantitative polymerase chain reaction. A new method that detects both the peripheral myelin protein 22 duplication in Charcot-Marie-Tooth type $1 \mathrm{~A}$ disease and the peripheral myelin protein 22 deletion in hereditary neuropathy with liability to pressure palsies. Hum Genet 2000, 107:494-498.

51. Pfaffl MW: A new mathematical model for relative quantification in realtime RT-PCR. Nucleic Acids Res 2001, 29:e45.

doi:10.1186/1749-8104-5-18

Cite this article as: Boukhtouche et al:: Induction of early Purkinje cell dendritic differentiation by thyroid hormone requires ROR $\alpha$. Neural Development 2010 5:18

\section{Submit your next manuscript to BioMed Central and take full advantage of:}

- Convenient online submission

- Thorough peer review

- No space constraints or color figure charges

- Immediate publication on acceptance

- Inclusion in PubMed, CAS, Scopus and Google Scholar

- Research which is freely available for redistribution 